\title{
Efeito das Dietas de Baixo Teor de Proteína Bruta, Suplementadas com Aminoácidos, para Leitões Machos Castrados $(15 \text { a } 30 \mathrm{~kg})^{1}$
}

\section{Gisele Cristina de Oliveira ${ }^{2,4}$, Ivan Moreira ${ }^{3,4}$, Antônio Claúdio Furlan ${ }^{3,4}$, Alexandre Orio Bastos $^{2}$, Alessandro Luís Fraga ${ }^{2}$}

\begin{abstract}
RESUMO - Foi conduzido um experimento, objetivando avaliar o efeito de dietas de baixo teor de proteína bruta, suplementadas com aminoácidos, sobre o desempenho de leitões machos castrados na fase inicial. Foram utilizados 40 suínos geneticamente melhorados, de linhagem fêmea comercial, distribuídos em delineamento experimental de blocos inteiramente casualizados, com quatro tratamentos, cinco blocos e dois animais por unidade experimental. Os quatro tratamentos foram: 18,73\% $\mathrm{P} 0,96 \% \mathrm{~L}$ - dieta à base de milho e de farelo de soja, contendo $18,73 \%$ de $\mathrm{PB}$ e $0,96 \%$ de lisina digestível; $16,86 \% \mathrm{P}+\mathrm{L}$ - dieta com nível de proteína $10 \%$ menor que o tratamento anterior, porém com nível de lisina corrigido; $16,86 \% \mathrm{P}+\mathrm{L}+\mathrm{M}+\mathrm{T}$ - dieta com nível de proteína $10 \%$ menor que a do primeiro tratamento. Os níveis de lisina, metionina + cistina e treonina foram corrigidos, com a adição de aminoácidos sintéticos, para atender ao padrão de proteína ideal; $17,79 \% \mathrm{P}+\mathrm{L}+\mathrm{M}+\mathrm{T}$ - semelhante ao tratamento anterior, porém com o nível de proteína $5 \%$ menor que o do primeiro tratamento. Não houve efeito sobre as variáveis de desempenho estudadas, nos períodos 0-14, 14-21 e 0-21 dias de avaliação do experimento. A redução da $\mathrm{PB}$, com correção dos aminoácidos, permitiu diminuir o nitrogênio da uréia plasmática (NUP). O custo em ração, por quilograma de peso vivo ganho, foi semelhante para todos os tratamentos. Os resultados indicam que o uso de dietas de baixo teor de proteína bruta, com suplementação de aminoácidos sintéticos, com base no conceito de proteína ideal, não prejudica o desempenho e as variáveis econômicas e, ainda, proporciona redução da excreção de nitrogênio.
\end{abstract}

Palavras-chave: aminoácidos sintéticos, baixo teor protéico, componente sangüíneo, dejetos, poluição ambiental

\section{Effect of Low Protein Diets with Amino Acid Supplementation on Barrow Starting (15 to $30 \mathrm{~kg}$ )}

ABSTRACT - A trial was carried out to evaluate the effect of low crude protein (CP) diets, supplemented with amino acids, on the starting barrows performance. Forty barrows genetically improved, of commercial dam line, were allotted to an experimental randomized complete block design, with four treatments, five blocks and two animals per experimental unit. The four treatments were: $18.73 \%$ P $.96 \% \mathrm{~L}$ - corn-soybean meal diet containing $18.73 \%$ of $\mathrm{CP}$ and $0.96 \%$ of digestible lysine; $16.86 \% \mathrm{P}+\mathrm{L}-$ it was constituted of a diet with $10 \%$ lower $\mathrm{CP}$ than previous and the lysine level was corrected; $16.86 \% \mathrm{P}+\mathrm{L}+\mathrm{M}+\mathrm{T}-$ it was formulated a diet with $10 \%$ lower CP than first treatment. The lysine, methionine + cystine and threonine level were corrected, with synthetic amino acids, to reach the ideal protein pattern; $17.79 \% \mathrm{P}+\mathrm{L}+\mathrm{M}+\mathrm{T}-$ it was similar to previous, however with $5 \%$ lower $\mathrm{CP}$ than that one obtained in the first treatment. There was no effect on performance, in the periods 0-14, 14-21 and 0-21 days of evaluation. The CP reduction was effective to decrease the plasma urea nitrogen (PUN). The cost in diet, per kilogram of gained live weight, was the same for all the treatments. The results indicated that diets with low crude protein, with synthetic amino acids supplementation, based on the ideal protein concept, do not impair the performance and economic variables, and furthermore provided the reduction in the nitrogen excretion.

Key Words: synthetic amino acids, slurry, low protein, blood components, environmental pollution

\section{Introdução}

A atividade suinícola tem buscado produzir animais com elevado potencial genético, para se obter carne magra. No entanto, segundo Perdomo \& Lima (1994), sua exploração é considerada, pelos órgãos de fiscalização ambiental, uma atividade de grande potencial poluidora.
O nitrogênio dos dejetos dos suínos é resultado da desaminação dos aminoácidos não utilizados para a síntese protéica, quando há excesso ou desbalanço de aminoácidos nas rações (Moreira et al., 2001).

Uma forma de reduzir a excreção de nitrogênio pelos suínos para o meio tem sido a utilização de dietas com níveis mais baixos de proteína bruta e

\footnotetext{
1 Parte da Dissertação de Mestrado da primeira autora junto ao Programa de Pós-graduação em Zootecnia da UEM.

2 Alunos do Programa de Pós-graduação em Zootecnia da UEM (gisele@mga.directlink.com.br)

3 Professores do DZO-UEM (Av. Colombo, 5790 CEP: 87020-900 Maringá, PR (imoreira@uem.br; acfurlan@uem.br)

4 Bolsista do CNPq.
} 
suplementação com aminoácidos sintéticos (Canh et al., 1998). Tem-se proposto o uso de dietas baseadas no conceito de proteína ideal, definida por Parsons \& Baker (1994), como sendo o balanço exato de aminoácidos capaz de prover, sem excesso ou déficit, os requerimentos de todos os aminoácidos necessários para a manutenção e máxima deposição protéica no organismo.

Dentro deste conceito, o aminoácido padrão utilizado é a lisina e, desta maneira, todos os demais aminoácidos são expressos em relação à lisina, pois, uma vez estabelecida sua exigência, pode-se calcular facilmente as exigências dos demais aminoácidos (Chung \& Baker, 1992). Entre os aminoácidos essenciais, a lisina, treonina, metionina e o triptofano são considerados como aminoácidos-chave (Hahn \& Baker, 1995) e, segundo Fraga (2002), na formulação de dietas, o modelo de proteína ideal geralmente é aplicado apenas aos aminoácidos mais limitantes nos ingredientes das rações.

A literatura tem mostrado diferentes recomendações de lisina para suínos em fase inicial (15 a $30 \mathrm{~kg}$ ). Benati (1996), compilando dados de dez empresas que atuam no mercado brasileiro, encontrou o valor médio de lisina total de $1,15 \%$. No entanto, o NRC (1998) recomenda o nível de $1,05 \%$, enquanto Rostagno et al. (2000) sugerem a exigência de lisina total de 1,28\% para fêmeas de alto potencial genético. Em recente publicação, Fraga (2002) determinou a exigência de lisina total para machos castrados de baixo e alto potencial genético $(0,80$ e $1,10 \%$, respectivamente), em dietas de baixo nível de proteína (14\%), formuladas de acordo com o conceito de proteína ideal.

Objetivou-se, com este trabalho, avaliar o efeito das dietas de baixo teor de proteína bruta, suplementadas com aminoácidos, para leitões machos castrados na fase inicial (15 a $30 \mathrm{~kg}$ ).

\section{Material e Métodos}

O experimento foi conduzido no período de outubro a novembro de 2001. A temperatura mínima média, dentro das instalações, foi de $20,9 \pm 1,7^{\circ} \mathrm{C}$ e a máxima média, de $32,4 \pm 3,6^{\circ} \mathrm{C}$.

Os animais foram alojados em duas salas de creche de alvenaria, coberta com telha de fibrocimento, sendo estas divididas em dez baias, separadas por corredor central. As baias eram de piso suspenso, com $1 / 3$ em piso plástico vazado. Cada baia possuía um comedouro na parte frontal (com cinco bocas) e um bebedouro tipo chupeta no fundo da baia.

Foram utilizados 40 leitões machos castrados, híbridos (Large-White x Landrace/Large-White), da linhagem fêmea de genética SEGHERS ${ }^{\circledR}$, com peso inicial médio de $15,80 \pm 1,17 \mathrm{~kg}$ e potencial genético para elevada produção de carne magra.

O delineamento experimental foi em blocos inteiramente casualizados, com quatro tratamentos, cinco blocos e dois animais por unidade experimental. $\mathrm{O}$ parentesco e o peso inicial dos leitões foram considerados para formação dos blocos.

Para o cálculo das dietas, foram determinados, em laboratório, os valores de proteína bruta e de energia bruta do milho e do farelo de soja utilizados

\begin{tabular}{|c|c|c|}
\hline \multicolumn{3}{|c|}{$\begin{array}{l}\text { Valores de energia metabolizável e } \\
\text { aminoácidos digestíveis, calculados a partir } \\
\text { dos valores de energia bruta e de proteína } \\
\text { bruta, determinados para o milho e farelo de } \\
\text { soja, utilizados nas rações experimentais } \\
\text { Metabolizable energy, digestible amino acids } \\
\text { values, calculated according to the analysed crude } \\
\text { energy and protein value of yellow corn and soybean } \\
\text { meal, used in the experimental diets }\end{array}$} \\
\hline Itens & Milho & Farelo de soja \\
\hline Items & Yellow corn & Soybean meal \\
\hline $\begin{array}{l}\text { Energia bruta }{ }^{1}, \mathrm{kcal} / \mathrm{kg} \\
\text { Crude energy }\end{array}$ & 3.879 & 4.201 \\
\hline $\begin{array}{l}\text { Coeficiente de } \\
\text { metabolizabilidade }^{2} \\
\text { Metabolizability coefficient }\end{array}$ & 0,847 & 0,766 \\
\hline $\begin{array}{l}\text { Energia metabolizável, } \mathrm{kcal} / \mathrm{kg} \\
\text { Metabolizable energy }\end{array}$ & 3.285 & 3.218 \\
\hline Proteína bruta ${ }^{1}, \%$ & 8,32 & 44,88 \\
\hline $\begin{array}{l}\text { Crude protein } \\
\text { Lisina digestível }^{3}, \% \\
\text { Digestible lysine }\end{array}$ & 0,1932 & 2,425 \\
\hline $\begin{array}{l}\text { Metionina+ cistina } \\
\text { digestíveis } 3, \%\end{array}$ & 0,3233 & 1,122 \\
\hline $\begin{array}{l}\text { Digestible met }+ \text { cyst } \\
\text { Treonina digestível }^{3}, \% \\
\text { Digestible threonine }\end{array}$ & 0,2534 & 1,488 \\
\hline $\begin{array}{l}\text { Triptofano digestível }{ }^{3}, \% \\
\text { Digestible tryptophan }\end{array}$ & 0,0466 & 0,572 \\
\hline
\end{tabular}

1 Valores determinados no Laboratório de Alimentos e Nutrição Animal (LANA) da UEM. (Values were determined on Feed and Animal Nutrition Laboratory (LANA) of UEM).

2 Coeficiente de metabolizabilidade da energia para o milho e o farelo de soja (Rostagno, 2000). (Metabolizability coefficient of energy of yellow corn and soybean meal [Rostagno et al., 2000]).

3 Proporcionalizados de acordo com o conteúdo indicado por Rostagno (2000) e o teor de proteína bruta determinada (Adjusted according to the content indicated from Rostagno (2000) and the meaning of determined crude protein). 
Tabela 2 - Padrão ideal de aminoácidos limitantes para suínos na fase inicial de crescimento, com base no conceito de proteína ideal

Table 2 - Ideal pattern of limiting amino acids for barrows, based on the concept of ideal protein

\begin{tabular}{lr}
\hline Aminoácido & Padrão ideal (\% da lisina digestível) \\
${\text { Amino } \text { acid }^{1}}^{\text {Ideal pattern (\% of digestible lysine) }}{ }^{1}$ \\
\hline
\end{tabular}

Lisina digestível 100

Digestible lysine

Metionina + cistina digestíveis

Digestible met + cys

Treonina digestível

Digestible threonine

Triptofano digestível

Digestible tryptophan

1 Calculado usando o software do NRC (1998), considerando suíno macho castrado com 22,5 kg (média entre 15 e $30 \mathrm{~kg}$ ) de peso vivo, $3.264 \mathrm{Kcal} E M / \mathrm{kg}$ e $325 \mathrm{~g}$ de ganho de carne magra/dia.

${ }^{1}$ Calculated using the NRC software (1998), considering barrows with 22,5 $\mathrm{kg}$ (averaging between 15 and $30 \mathrm{~kg}$ ) of body weight, $3.264 \mathrm{Kcal}$ EM/kg and $325 \mathrm{~g}$ of lean gain/day.

como ingredientes (Tabela 1). A proporcionalização do conteúdo de aminoácidos digestíveis foi feita em relação à proteína bruta e o cálculo da energia metabolizável, a partir dos valores de Rostagno et al. (2000), considerando-se o conteúdo de lisina $(23,4 \%)$ contido no suplemento vitamínico-mineral.

O padrão de proteína ideal (Tabela 2), utilizado na elaboração das dietas, considerou suínos machos castrados com $325 \mathrm{~g}$ de ganho de carne magra/dia, de $22,5 \mathrm{~kg}$ de peso vivo e valor energético da ração de $3.264 \mathrm{kcal}$ de EM/kg, conforme NRC (1998).

Os tratamentos consistiram de quatro dietas práticas (Tabela 3), à base de milho, farelo de soja, óleo de soja, fosfato bicálcico, calcário calcítico, sal comum $(\mathrm{NaCl})$ e suplemento vitamínico-mineral. Os níveis de energia metabolizável, cálcio e fósforo disponível, em todos os tratamentos, foram os mesmos e corresponderam àqueles utilizados rotineiramente na suinocultura industrial e atenderam às exigências de suínos na fase inicial de crescimento, de acordo com as recomendações do NRC (1998).

Os quatro tratamentos foram:

$\mathbf{1 8 , 7 3 \% P} \mathbf{0 , 9 6 \% L}$ : constituiu-se de uma dieta contendo $0,96 \%$ de lisina digestível, conforme indicado por Fraga (2002), e 18,73\% de PB. Não foram adicionados aminoácidos sintéticos, tendo como restrição na matriz de cálculo apenas a lisina. Os níveis de proteína bruta, metionina + cistina, treonina e triptofano foram aqueles alcançados com a mistura de milho e farelo de soja, para atingir o nível de lisina desejado $(0,96 \%)$.
16,86P + L: constituiu-se de uma dieta com nível de proteína $10 \%$ menor que a do tratamento anterior. O nível de lisina foi corrigido para o mesmo nível do tratamento anterior, com adição de L-Lisina $\mathrm{HCl}$.

$\mathbf{1 6 , 8 6 \%} \mathbf{P}+\mathbf{L}+\mathbf{M}+\mathbf{T}:$ constituiu-se de uma dieta com nível de proteína $10 \%$ menor que a do primeiro tratamento, com correção dos níveis de lisina, que foi o mesmo do primeiro tratamento, bem como de metionina + cistina e treonina, por meio da adição de aminoácidos sintéticos, para atender ao padrão de proteína ideal (Tabela 2), indicado pelo NRC (1998).

$\mathbf{1 7 , 7 9 \%} \mathbf{P}+\mathbf{L}+\mathbf{M}+\mathbf{T}$ : constituiu-se de uma dieta com o nível de proteína 5\% menor que aquela obtida no primeiro tratamento, sendo corrigidos os níveis de lisina, metionina + cistina e treonina, semelhantemente ao tratamento anterior.

As composições química e energética das dietas experimentais são apresentadas na Tabela 4 .

As rações e a água foram fornecidas à vontade. As pesagens dos animais e das rações foram feitas ao início, aos 14 dias e ao final do experimento. Foram calculados o consumo diário de ração (CDR), o ganho diário de peso (GDP) e a conversão alimentar (CA), referentes a cada período de pesagem $(0-14,14-21$ e 0-21 dias).

Amostras de sangue foram colhidas, sempre das 8 às 9h30, através de punção da veia cava cranial, no início ("baseline") e final do experimento, para determinação do teor de nitrogênio da uréia plasmática (NUP). As coletas de sangue foram realizadas, após as pesagens dos animais, sem jejum, seguindo as indicações de Cai et al. (1994). Retiraram-se em torno de $10 \mathrm{~mL}$ de sangue em tubos contendo heparina, que foi centrifugado a $3.000 \mathrm{rpm}$, durante 15 minutos, para a obtenção do plasma. Os tubos com o plasma foram identificados e armazenados a $-20^{\circ} \mathrm{C}$.

A dosagem do NUP foi realizada pelo método enzimático, utilizando-se o Kit Diasys da MERCKâa sendo o valor obtido (teor de uréia) multiplicado pelo fator 0,467 , que representa a fração de nitrogênio na molécula de uréia (Newman \& Price, 1999). A dosagem do NUP no início do experimento ("baseline") foi utilizada como covariável na análise estatística do NUP dosado no final do experimento.

Foi calculada a eficiência de utilização de nitrogênio para ganho (EUNG), segundo a fórmula: $\mathrm{EUNG}=\mathrm{gGDP} / \mathrm{gN}$, em que gGDP é o ganho diário de peso, em gramas por dia (g/d), e gN, o consumo de nitrogênio, em g/d. 
Tabela 3 - Composição centesimal das rações fornecidas aos suínos na fase inicial de crescimento, para os diferentes tratamentos

Table 3 - Centesimal composition of experimental diets fed to barrows of different treatments

\begin{tabular}{|c|c|c|c|c|}
\hline \multirow[t]{2}{*}{$\begin{array}{l}\text { Ingredientes } \\
\text { Ingredients }\end{array}$} & \multicolumn{4}{|c|}{$\begin{array}{c}\text { Tratamentos } 1 \\
\text { Treatments }\end{array}$} \\
\hline & $18,73 \% \mathrm{P} 0,96 \%$ & $\mathrm{~L} 16,86 \% \mathrm{P}+\mathrm{L}$ & $16,86 \% \mathrm{P}+\mathrm{L}+\mathrm{M}+\mathrm{T}$ & $17,79 \% \mathrm{P}+\mathrm{L}+\mathrm{M}+\mathrm{T}$ \\
\hline Milho & 65,87 & 71,22 & 71,28 & 68,59 \\
\hline \multicolumn{5}{|l|}{ Yellow corn } \\
\hline Farelo de soja & 29,52 & 24,03 & 23,81 & 26,65 \\
\hline \multicolumn{5}{|l|}{ Soybean meal } \\
\hline Óleo de soja & 1,83 & 1,76 & 1,78 & 1,80 \\
\hline \multicolumn{5}{|l|}{ Soybean oil } \\
\hline Fosfato bicálcico & 1,10 & 1,15 & 1,15 & 1,13 \\
\hline \multicolumn{5}{|l|}{ Dicalcium phosphate } \\
\hline Calcário calcítico & 0,68 & 0,69 & 0,69 & 0,68 \\
\hline \multicolumn{5}{|l|}{ Limestone } \\
\hline Sal & 0,40 & 0,40 & 0,40 & 0,40 \\
\hline \multicolumn{5}{|l|}{ Salt } \\
\hline Supl. Vit-mineral ${ }^{2}$ & 0,50 & 0,50 & 0,50 & 0,50 \\
\hline \multicolumn{5}{|l|}{ Vit. $+\min . \operatorname{mix}^{2}$} \\
\hline Promotor de crescimento ${ }^{3}$ & 0,10 & 0,10 & 0,10 & 0,10 \\
\hline \multicolumn{5}{|l|}{ Growth promoter } \\
\hline DL-metionina, $99,0 \%$ & 0,00 & 0,00 & 0,05 & 0,03 \\
\hline \multicolumn{5}{|l|}{ DL-methionine } \\
\hline L-lisina $\mathrm{HCl}, 78,4 \%$ & 0,00 & 0,16 & 0,17 & 0,08 \\
\hline \multicolumn{5}{|l|}{ L-lysine } \\
\hline L-treonina, 98,0\% & 0,00 & 0,00 & 0,07 & 0,03 \\
\hline \multicolumn{5}{|l|}{ L-threonine } \\
\hline Total & 100,00 & 100,00 & 100,00 & 100,00 \\
\hline
\end{tabular}

$1 \mathbf{1 8}, \mathbf{7 3} \% \mathbf{P}, \mathbf{0 , 9 6 \%} \mathrm{L}=$ Ração com $18.73 \%$ de $\mathrm{PB}$ e $0,96 \%$ de lisina; $\mathbf{1 6 , 8 6} \% \mathbf{P + L}=$ Ração com $10 \%$ menos de $P B+$ adição $L-$ lisina; $\mathbf{1 6 , 8 6 \%} \mathbf{P}+\mathrm{L}+\mathbf{M}+\mathbf{T}=$ Ração com $10 \%$ menos de PB + adição L-lisina, DL-metionina e L-treonina; $17,79 \% \mathrm{P}+\mathrm{L}+\mathbf{M}+\mathbf{T}=\mathrm{R}=\mathrm{R}$ aça com $5 \%$

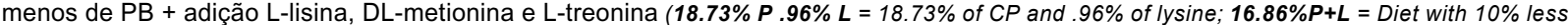
$C P+L$-lysine; $\mathbf{1 6 . 8 6 \%} P+L+M+T=$ Diet with $10 \%$ less $C P+L$-lysine, $D L$-methionine e $L$-threonine; $17.79 \% P+L+M+T=D i e t$ with $5 \%$ less $C P+L-l y$ sine, $D L-$ methionine and L-threonine).

2 Suplemento vitamínico e mineral (vitamin and mineral supplement) - Composição por kg do produto (Composition per kg of product): Ác. Fólico (folacin) - 200,0 mg; Vit. A - 2.000.000 UI; Selênio (selenium) - 60,0 mg; Lisina (lysine) - 234.000,0 mg; Colina (choline) - 30.000,0 mg; Ác. Pantotênico (pantothenic acid) - 2.400,0 mg; Ác. Nicotínico (niacin) - 6.000,0 mg; Vit. B12 - 6.000,0 mcg; Vit. B6 - 600,0 mg; Vit. B2 - 1.200,0 mg; Vit. B1 - 400,00 mg; Vit. K3 - 400,0 mg; Vit. E - 5.000 UI; Vit. D3 - 400.000 UI; Biotina (biotin) - 20,0 mg; Promotor de crescimento (growth promoter) - 10.000,0 mg; lodo (iodine) - 300,0 mg; Cobalto (cobalt) - 200,0 mg; Cobre (copper) - 35.000,0 mg; Zinco (zinc) - 20.000,0 mg; Ferro (iron) - 20.000 mg; Manganês (manganese) - 8.000,0 mg; Antioxidante (antioxidant) - 20.000,0 mg; Veículo q.s.p.- 1.000,0 g.

3 Fosfato de tilosina (Tylosin phosphate) - Composição por kg do produto (Composition per kg of product): Fosfato de tilosina (tylosin phosphate) - 100,0 g; sulfametazina (sulfamethazine) - 100,0 g; Veículo q.s.p. - 1.000,0 g.

$\mathrm{O} g \mathrm{~g}$ é obtido pela fórmula: $\mathrm{gN}=[(\mathrm{CDR} \times \mathrm{PB}) /$ 100]/6,25, em que CDR é o consumo diário de ração, em g/d e PB, o nível de proteína bruta da ração.

As variáveis econômicas foram analisadas de acordo com Bellaver et al. (1985), sendo inicialmente determinado o custo médio em ração, por quilograma de peso vivo ganho, referentes a todo período experimental. Em seguida, foram calculados o índice de eficiência econômica (IEE) e o índice de custo médio, propostos por Barbosa et al. (1992).

Os preços dos ingredientes utilizados na elaboração dos custos foram coletados no mês de abril de 2002: milho, R\$ 0,217/kg; farelo de soja, R\$ 0,365/kg; óleo de soja, R\$ 0,95/kg; fosfato bicálcico, R $\$ 0,716 / \mathrm{kg}$; calcário calcítico, $\mathrm{R} \$ 0,08 / \mathrm{kg}$; sal comum, $\mathrm{R} \$ 0,30 / \mathrm{kg}$; promotor de crescimento, R\$ $31,29 / \mathrm{kg}$; suplemento vitamínico-mineral, $\mathrm{R} \$ 4,52 / \mathrm{kg}$; L-lisina $\mathrm{HCl}, \mathrm{R} \$ 5,52 / \mathrm{kg}$; DL-metionina, R\$ 7,44/kg; L-treonina, R\$ 13,92/kg; e L-triptofano, $\mathrm{R} \$ 254,4 / \mathrm{kg}$.

As variáveis analisadas foram desempenho (consumo de ração, ganho de peso e conversão alimentar), NUP, EUNG e variáveis econômicas.

As variáveis estudadas foram submetidas à análise de variância e teste de médias (teste de NewmanKeuls, $\mathrm{P}<0,05$ ), utilizando o pacote estatístico SAEG, de acordo com o seguinte modelo matemático:

$$
\mathrm{Y}_{i j k}=\mu+\mathrm{Tj}+\mathrm{Bk}+e_{i j k}
$$

em que $\mathrm{Y}_{i j k}=$ valor observado das variáveis estuda-

R. Bras. Zootec., v.33, n.6, p.1747-1757, 2004 (Supl. 1) 
Tabela 4 - Composições química e energética das rações fornecidas aos suínos na fase inicial de crescimento, para os diferentes tratamentos

Table 4 - Chemical and energy composition of the experimental diets fed to barrows of different treatments

\begin{tabular}{|c|c|c|c|c|}
\hline \multirow[t]{2}{*}{$\begin{array}{l}\text { Ingredientes } \\
\text { Ingredients }\end{array}$} & \multicolumn{4}{|c|}{$\begin{array}{c}\text { Tratamentos }^{1} \\
\text { Treatments }^{1}\end{array}$} \\
\hline & $18,73 \%$ P $0,96 \%$ & $\mathrm{~L} 16,86 \% \mathrm{P}+\mathrm{L}$ & $16,86 \% \mathrm{P}+\mathrm{L}+\mathrm{M}+\mathrm{T}$ & $17,79 \% \mathrm{P}+\mathrm{L}+\mathrm{M}+\mathrm{T}$ \\
\hline & \multicolumn{4}{|c|}{$\begin{array}{l}\text { Valores calculados } \\
\text { Calculated values }\end{array}$} \\
\hline $\begin{array}{l}\text { PB calculada, } \% \\
\text { Calculated } C P\end{array}$ & 18,729 & 16,860 & 16,860 & 17,790 \\
\hline $\mathrm{EM}(M E), \mathrm{kcal} / \mathrm{kg}$ & 3.264 & 3.264 & 3.264 & 3.264 \\
\hline $\begin{array}{l}\text { Cálcio (\%) } \\
\text { Calcium }\end{array}$ & 0,650 & 0,650 & 0,650 & 0,650 \\
\hline Fósforo disponível (\%) & 0,270 & 0,270 & 0,270 & 0,270 \\
\hline $\begin{array}{l}\text { Available phosphorus } \\
\text { Lis digestível (\%) } \\
\text { Digestible lysine }\end{array}$ & 0,960 & 0,960 & 0,960 & 0,960 \\
\hline $\begin{array}{l}\text { Met }+ \text { Cist digestíveis (\%) } \\
\text { Digestible met }+ \text { cys }\end{array}$ & 0,545 & 0,500 & 0,550 & 0,550 \\
\hline Treo digestível (\%) & 0,606 & 0,538 & 0,600 & 0,600 \\
\hline $\begin{array}{l}\text { Digestible threonine } \\
\text { Tript digestível (\%) } \\
\text { Digestible trvtophan }\end{array}$ & 0,199 & 0,180 & 0,180 & 0,184 \\
\hline $\begin{array}{l}\text { Relação lisina:PB } \\
\text { Lysine: } P B \text { ratio }\end{array}$ & 5,1 & 5,7 & 5,7 & 5,4 \\
\hline $\begin{array}{l}\text { Lysine: } \mathrm{PB} \text { ratıo } \\
\mathrm{BED}^{3}, \mathrm{mEq} / \mathrm{kg} \\
\mathrm{Na}+\mathrm{K}-\mathrm{Cl}\end{array}$ & 201,88 & 165,88 & 165,11 & 188,90 \\
\hline
\end{tabular}

$1 \mathbf{1 8}, \mathbf{7 3} \% \mathbf{P}, \mathbf{0 , 9 6 \%} \mathbf{L}=$ Ração com $18.73 \%$ de PB e $0,96 \%$ de lisina; $\mathbf{1 6 , 8 6} \% \mathbf{P + L}=$ Ração com $10 \%$ menos de PB + adição L-lisina;

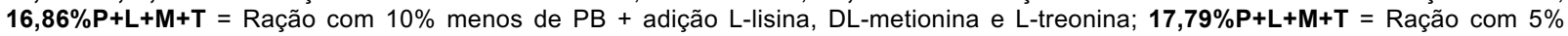

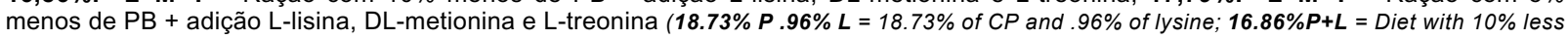
$C P+L$-lysine; $\mathbf{1 6 . 8 6 \%} P+L+M+T=$ Diet with $10 \%$ less $C P+L$-lysine, $D L$-methionine e $L$-threonine; $17.79 \% P+L+M+T=D i e t$ with $5 \%$ less $C P+L-l y$ sine, $D L$-methionine and $L$-threonine).

2 Valores determinados na LANA da UEM (Values were determined at LANA of UEM).

${ }^{3}$ Valores calculados com base nas Tabelas 1 e 3 (Calculated values with basis on theTables 1 and 3).

4 Valores calculados pela fórmula de Mongin (Patience, 1990), utilizando-se os valores dos alimentos indicados por Rostagno et al. (2000)

${ }^{4}$ Values calculated according to Mongin formula (Patience, 1990), using the value of feed indicated by Rostagno et al. (2000).

das, relativo a cada indivíduo $k$, recebendo o tratamento $\mathrm{j}$, no bloco $\mathrm{k} ; \mu=$ constante geral; $\mathrm{T}_{j}=$ efeito do tratamento, sendo $j=1,2,3$ e $4 ; \mathrm{B}_{k}=$ efeito do bloco, sendo $k=1,2,3,4$ e 5 ; $e_{i j k}=$ erro aleatório associado a cada observação.

\section{Resultados e Discussão}

Os níveis de proteína bruta e aminogramas do milho e do farelo de soja utilizados como ingredientes das rações experimentais são apresentados na Tabela 5 .

Os resultados do peso inicial, consumo diário de ração (CDR), ganho diário de peso (GDP), conversão alimentar (CA), concentração do nitrogênio da uréia plasmática (NUP) e eficiência de utilização de nitrogênio para ganho (EUNG), em função dos diferentes tratamentos, são apresentados na Tabela 6.
Não houve efeito $(\mathrm{P}>0,05)$ dos tratamentos sobre CDR, GDP e CA, em nenhum dos períodos experimentais.

Como os efeitos $(\mathrm{P}>0,05)$ dos tratamentos sobre as variáveis de desempenho nos períodos 0-14, 14-21 e 0-21 dias de avaliação foram os mesmos, a discussão baseou-se no período total do experimento.

O CDR foi semelhante $(\mathrm{P}>0,05)$ nos diferentes tratamentos, fato que corrobora os resultados obtidos por Ferreira et al. (2001), que não verificaram efeito da redução da $\mathrm{PB}$ da dieta sobre o consumo de ração, trabalhando com suínos na fase inicial (15 a $30 \mathrm{~kg}$ ), alimentados com dietas com níveis decrescentes de proteína bruta $(18,16,15$ e 14\%), suplementadas com aminoácidos sintéticos (Lis, Met e Tre). Entretanto, Le Bellego \& Noblet (2002) observaram menor consumo de ração por animais que receberam dieta com alto nível de $\mathrm{PB}(22,4 \%)$, comparado àqueles que

R. Bras. Zootec., v.33, n.6, p.1747-1757, 2004 (Supl. 1) 
Tabela 5 - Níveis de proteína bruta e composição aminoacídica do milho, farelo de soja e das rações experimentais 1 Table 5 - Crude protein and amino acid composition of yellow corn, soybean meal and experimental diets ${ }^{1}$

\begin{tabular}{|c|c|c|c|c|c|c|}
\hline \multirow[t]{2}{*}{$\begin{array}{l}\text { Nutriente (\%) } \\
\text { Nutrient }\end{array}$} & \multirow[t]{2}{*}{$\begin{array}{l}\text { Milho } \\
\text { Yellow corn }\end{array}$} & \multirow[t]{2}{*}{$\begin{array}{c}\text { Farelo de soja } \\
\text { Soybean meal }\end{array}$} & \multicolumn{4}{|c|}{$\begin{array}{c}\text { Tratamentos }^{2} \\
\text { Treatments } \\
\end{array}$} \\
\hline & & & $18,73 \%$ P $0,96 \% \mathrm{~L}$ & $16,86 \% \mathrm{P}+\mathrm{L}$ & $16,86 \% \mathrm{P}+\mathrm{L}+\mathrm{M}+\mathrm{T}$ & $17,79 \% \mathrm{P}+\mathrm{L}+\mathrm{M}+\mathrm{T}$ \\
\hline $\begin{array}{l}\text { Proteína bruta } \\
\text { Crude protein } \\
\text { Aminoácidos essenciais } \\
\text { Essential amino acids }\end{array}$ & $8,32^{3}$ & $44,88^{3}$ & 18,73 & 16,86 & 16,86 & 17,79 \\
\hline $\begin{array}{l}\text { Lisina } \\
\text { Lysine }\end{array}$ & 0,25 & 2,57 & 1,04 & 1,04 & 1,04 & 1,04 \\
\hline $\begin{array}{l}\text { Met+Cis } \\
\text { Met }+ \text { Cys }\end{array}$ & 0,38 & 1,26 & 0,62 & 0,57 & 0,57 & 0,60 \\
\hline $\begin{array}{l}\text { Treonina } \\
\text { Threonine }\end{array}$ & 0,30 & 1,70 & 0,70 & 0,62 & 0,69 & 0,69 \\
\hline $\begin{array}{l}\text { Triptofano } \\
\text { Tryptophan }\end{array}$ & 0,06 & 0,79 & 0,28 & 0,24 & 0,23 & 0,25 \\
\hline $\begin{array}{l}\text { Valina } \\
\text { Valine }\end{array}$ & 0,38 & 2,06 & 0,85 & 0,76 & 0,76 & 0,81 \\
\hline $\begin{array}{l}\text { Metionina } \\
\text { Methionine }\end{array}$ & 0,19 & 0,60 & 0,30 & 0,28 & 0,33 & 0,32 \\
\hline $\begin{array}{l}\text { Histidina } \\
\text { Histidine }\end{array}$ & 0,24 & 1,10 & 0,48 & 0,44 & 0,43 & 0,46 \\
\hline $\begin{array}{l}\text { Arginina } \\
\text { Arginine }\end{array}$ & 0,40 & 3,16 & 1,20 & 1,05 & 1,04 & 1,12 \\
\hline $\begin{array}{l}\text { Leucina } \\
\text { Leucine }\end{array}$ & 0,97 & 3,20 & 1,58 & 1,46 & 1,45 & 1,52 \\
\hline $\begin{array}{l}\text { Isoleucina } \\
\text { Isoleucine }\end{array}$ & 0,26 & 1,98 & 0,76 & 0,66 & 0,66 & 0,71 \\
\hline $\begin{array}{l}\text { Fenilalanina+tirosina } \\
\text { Phenylalanine }+ \text { tyrosine }\end{array}$ & 0,63 & 4,29 & 1,68 & 1,48 & 1,47 & 1,57 \\
\hline $\begin{array}{l}\text { Aminoácidos não-essen } \\
\text { Non essential amino acids }\end{array}$ & hciais & & & & & \\
\hline $\begin{array}{l}\text { Glicina } \\
\text { Glicine }\end{array}$ & 0,32 & 1,03 & 0,52 & 0,48 & 0,47 & 0,49 \\
\hline $\begin{array}{l}\text { Ác. glutâmico } \\
\text { Glutamic acid }\end{array}$ & 1,47 & 7,57 & 3,20 & 2,86 & 2,85 & 3,02 \\
\hline $\begin{array}{l}\text { Alanina } \\
\text { Alanine }\end{array}$ & 0,61 & 1,82 & 0,94 & 0,87 & 0,87 & 0,90 \\
\hline $\begin{array}{l}\text { Serina } \\
\text { Serine }\end{array}$ & 0,41 & 2,26 & 0,94 & 0,84 & 0,83 & 0,89 \\
\hline $\begin{array}{l}\text { Ác. aspártico } \\
\text { Aspartic acid }\end{array}$ & 0,51 & 4,86 & 1,77 & 1,53 & 1,52 & 1,65 \\
\hline
\end{tabular}

${ }^{1}$ Valores calculados a partir de análises laboratoriais realizadas pela Ajinomoto Animal Nutrition (Calculated values from laboratories analysis made of Ajinomoto Animal Nutrition).

$2 \mathbf{1 8}, \mathbf{7 3} \% \mathbf{P}, \mathbf{0 , 9 6} \% \mathbf{L}=$ Ração com $18.73 \%$ de $\mathrm{PB}$ e $0,96 \%$ de lisina; $\mathbf{1 6 , 8 6} \% \mathbf{P + L}=$ Ração com $10 \%$ menos de $\mathrm{PB}+$ adição $\mathrm{L}-$ lisina; $\mathbf{1 6 , 8 6 \%} \mathbf{P + L + M + T}=$ Ração com $10 \%$ menos de $P B+$ adição L-lisina, DL-metionina e L-treonina; $\mathbf{1 7 , 7 9 \% P + L + M + T ~ = ~ R a c ̧ a ̃ o ~ c o m ~ 5 \% ~ m e n o s ~}$ de $P B+$ adição L-lisina, DL-metionina e L-treonina $(18.73 \% P .96 \% L=18.73 \%$ of $C P$ and $.96 \%$ of lysine; $16.86 \% P+L=D i e t$ with $10 \%$ less $C P+$

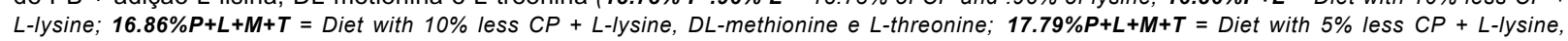
$D L$-methionine and L-threonine).

3 Valores determinados no Laboratório de Alimentos e Nutrição Animal (LANA) da UEM (Values were determined at the feed and animal nutrition laboratory (LANA) of UEM).

receberam dietas com menores níveis de PB $(20,4$; $18,4$ e $16,9 \%)$, suplementados com aminoácidos. Esses autores associaram esse fato ao excesso e/ou desbalanço dos aminoácidos que poderiam ter afetado negativamente o consumo de ração.
Segundo Patience \& Chaplin (1997), a variação do balanço eletrolítico das dietas é um fator que afeta as condições fisiológica e metabólica dos suínos e, portanto, deveria ser considerado na avaliação de resultados de experimentos. De acordo com Patience 


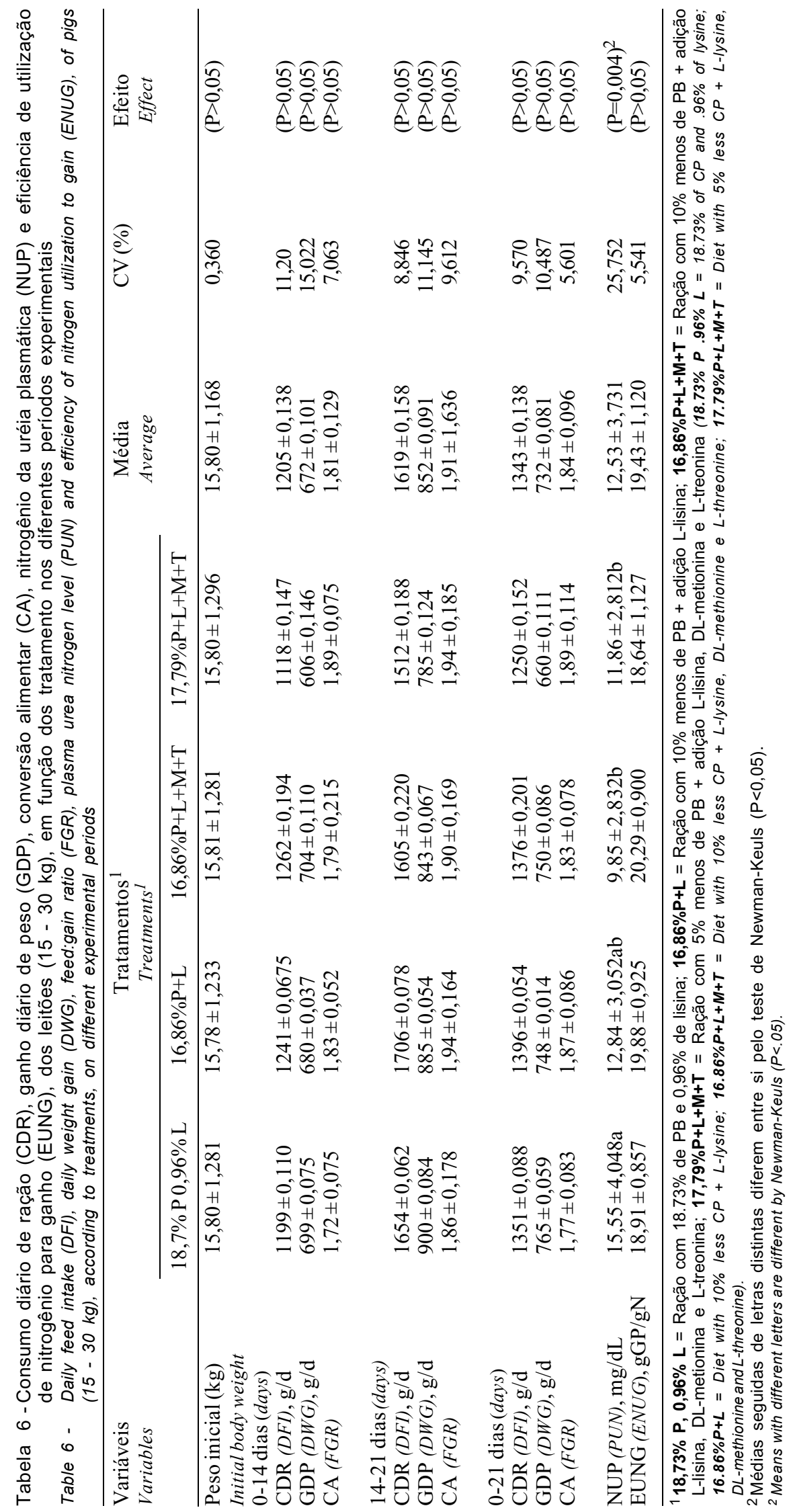


et al. (1987), o valor do balanço eletrolítico dietético (BED) de uma dieta para máximo crescimento e consumo deve estar entre 0 e $341 \mathrm{mEq} / \mathrm{kg}$. Neste experimento, com a redução dos níveis protéicos e a suplementação com aminoácidos sintéticos nas dietas, ocorreu diminuição no BED (Tabela 4), variando de 165,11 a $201,88 \mathrm{mEq} / \mathrm{kg}$, estando dentro da faixa estipulada pelos autores acima citados. Espera-se que a BED não tenha influenciado o desempenho dos leitões. Resultado semelhante foi observado por Fraga (2002), que não encontrou influência da BED sobre o CDR.

Diferentes níveis de PB na dieta, com ou sem correção dos níveis de aminoácidos, não influenciaram ( $\mathrm{P}>0,05)$ o GDP. Resultados similares foram encontrados por Kerr et al. (1995), que não observaram melhora no GDP, ao fornecer EM rações para suínos nas fases inicial $(8,6$ a $21,1 \mathrm{~kg})$ e de crescimento $(21,1$ a $55,2 \mathrm{~kg}$ ) com altos (19 e 16\%) e baixos níveis (14 e $12 \%$ de $\mathrm{PB}$, respectivamente), suplementadas com aminoácidos sintéticos.

Não houve efeito $(\mathrm{P}>0,05)$ do nível de $\mathrm{PB}$ da dieta, com ou sem correção de aminoácidos, sobre a CA. Estes resultados estão de acordo com aqueles obtidos por Tuitoek et al. (1997), que não observaram efeito de dietas com níveis de PB entre 16,6 e 13,0\%, suplementadas com aminoácidos sintéticos, sobre a CA de suínos na fase de crescimento (20 a $55 \mathrm{~kg}$ ). Coelho et al. (1987) e Ferreira et al. (2001) também não encontraram efeito da redução dos níveis de proteína bruta com a suplementação de aminoácidos sintéticos, sobre a CA de suínos na fase inicial.

Animais alimentados com dietas com nível reduzido de PB, com aplicação do conceito de proteína ideal, com a suplementação de aminoácidos, tiveram desempenho semelhante àqueles alimentados com dietas com alto nível de proteína. Este fato pode estar associado à adequada relação dos aminoácidos essenciais necessários para suprir as exigências requeridas na manutenção e deposição protéica corporal dos animais.

Considerando o nível de lisina digestível de $0,96 \%$ determinada por Fraga (2002) e, seguindo o conceito de proteína ideal, as exigências de treonina digestível, metionina + cistina digestíveis e triptofano digestível foram 0,$60 ; 0,55$ e $0,18 \%$, respectivamente. $O$ valor de treonina digestível utilizada neste experimento foi próximo ao obtido por Pozza et al. (1999), que, trabalhando com suínos machos castrados (15 a $30 \mathrm{~kg}$ ), encontraram exigência de treonina digestível verdadeira de $0,56 \%$.

Sabe-se que a absorção dos aminoácidos livres é mais rápida do que os aminoácidos derivados das proteínas intactas, podendo influenciar negativamente a eficiência de utilização dos aminoácidos e, por conseqüência, o desempenho dos animais (Lewis, 2001). Porém, a alimentação à vontade permite que a utilização dos aminoácidos seja eficaz (D’Mello, 1993). No presente experimento, ao reduzir os níveis de PB em 1,87 ( $2 \underline{0}$ e $3 \underline{o}$ tratamentos) e 0,94 pontos

Tabela 7 - Índices econômicos de suínos alimentados com dietas com diferentes níveis de proteína, com ou sem correção do nível de aminoácidos

Table 7 - Economic index of pigs fed diets with different protein levels, with or without amino acid addition

\begin{tabular}{|c|c|c|c|c|}
\hline \multirow[t]{2}{*}{$\begin{array}{l}\text { Itens } \\
\text { Items }\end{array}$} & \multicolumn{4}{|c|}{$\begin{array}{l}\text { Tratamentos } \\
\text { Treatments }^{1}\end{array}$} \\
\hline & $18,73 \% \mathrm{P} 0,96 \%$ & $\mathrm{~L} 16,86 \% \mathrm{P}+\mathrm{L}$ & $16,86 \% \mathrm{P}+\mathrm{L}+\mathrm{M}+\mathrm{T}$ & $17,79 \% \mathrm{P}+\mathrm{L}+\mathrm{M}+\mathrm{T}$ \\
\hline Custo da ração, $\mathrm{R} \$ / \mathrm{kg}$ & 0,33 & 0,33 & 0,35 & 0,34 \\
\hline $\begin{array}{l}\text { Diet cost } \\
\text { Custo em ração, } \mathrm{R} \$ / \mathrm{kg}^{2}\end{array}$ & 0,187 & 0,176 & 0,191 & 0,179 \\
\hline $\begin{array}{l}\text { Cost in diet } \\
\text { Indice de custo médio } \\
\text { Mean cost index }\end{array}$ & 106,2 & 100,0 & 108,4 & 101,4 \\
\hline $\begin{array}{l}\text { Índice de eficiência econômica } \\
\text { Economic efficiency index }\end{array}$ & 94,2 & 100,0 & 92,3 & 98,6 \\
\hline
\end{tabular}

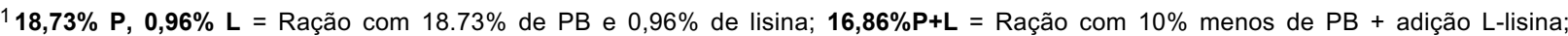
$\mathbf{1 6 , 8 6} \% \mathbf{P + L + M + T}=$ Ração com $10 \%$ menos de PB + adição L-lisina, DL-metionina e L-treonina; $\mathbf{1 7 , 7 9 \% P + L + M + T ~ = ~ R a c ̧ a ̃ o ~ c o m ~ 5 \% ~ m e n o s ~}$ de PB + adição L-lisina, DL-metionina e L-treonina (18.73\% P .96\% L = 18.73\% of CP and .96\% of lysine; $16.86 \% P+L=D i e t$ with $10 \%$ less $C P+$ $L$-lysine; $16.86 \% P+L+M+T=$ Diet with $10 \%$ less $C P+L$-lysine, $D L-$-methionine e L-threonine; $17.79 \% P+L+M+T=D i e t$ with $5 \%$ less $C P+L-l y$ sine, $D L$-methionine and L-threonine).

$2(P>0,05)$.
}

R. Bras. Zootec., v.33, n.6, p.1747-1757, 2004 (Supl. 1) 
percentuais (40 tratamento), não se observou diferença nas variáveis de desempenho, uma vez que os animais tiveram livre acesso às dietas, tornando os aminoácidos sintéticos disponíveis em nível celular, para participarem da síntese protéica ao mesmo tempo que os aminoácidos provenientes das proteínas intactas.

A redução do nível de $\mathrm{PB}$, neste experimento, foi em torno de 2 pontos percentuais e, mesmo assim, não se observou comprometimento do desempenho dos leitões. Da mesma forma que alguns autores, que reduziram o teor de $\mathrm{PB}$ em 4 pontos percentuais, com adequada suplementação de aminoácidos sintéticos, e não observaram alterações no desempenho de suínos nas fases inicial (Hansen et al., 1993; Ferreira et al., 2001), de crescimento (Tuitoek et al., 1997; Pieterse et al., 2000) e terminação (Canh et al., 1998; Knowles et al., 1998). Entretanto, Kendall et al. (1998) verificaram que a redução de 4,5 pontos percentuais dos níveis de $\mathrm{PB}$ afetou negativamente o desempenho dos animais e consideraram um limite de até 3,5 pontos percentuais nas rações de suínos em terminação, para prevenir prejuízo no desempenho.

Segundo Suida (2001), a relação lisina:PB pode ser uma forma prática de controlar o nível protéico mínimo usado para formular dietas de suínos. $O$ valor médio da relação lisina:PB obtida neste experimento, de 5,5\% (Tabela 4), está de acordo com Lee et al. (1998) e Li et al. (2001), que encontraram a adequada relação de lisina:PB para suínos em fase inicial (8 a $20 \mathrm{~kg}$ ), de 5,2 a $5,8 \%$.

Observou-se efeito $(\mathrm{P}=0,004)$ do nível de $\mathrm{PB}$, com ou sem correção de aminoácidos, sobre o NUP (Tabela 6). A redução da PB foi eficaz para diminuir o NUP. Os animais alimentados com dieta com maior nível de PB apresentaram NUP mais elevado que os alimentados com dietas contendo 10 ou $5 \%$ de redução de $\mathrm{PB}$, com correção de aminoácidos.

Os teores reduzidos do NUP referentes aos tratamentos com baixa PB indicam melhor adequação na ingestão de aminoácidos dietéticos, permitindo que os leitões alimentados com dietas de baixo nível protéico, suplementadas com aminoácidos sintéticos, utulizassem a proteína dietética mais eficientemente que os animais alimentados com dieta contendo alto nível protéico. Segundo Fraga (2002), o NUP é um eficiente parâmetro para indicar a utilização dos aminoácidos dietéticos pelo suíno.

A redução do nível de $\mathrm{PB}$, sem suplementação dos aminoácidos, não foi eficiente em reduzir o NUP, visto que os animais alimentados com dietas com
$18,73 \%$ de $\mathrm{PB}$ tiveram NUP semelhante àqueles alimentados com dietas com $16,86 \%$ de PB, o que demonstra desbalanceamento de aminoácidos e, em conseqüência, elevado NUP em ambos os casos.

Resultados semelhantes aos do presente trabalho foram observados por Kerr \& Easter (1995), que encontraram redução dos níveis de NUP de suínos na fase de terminação (70 a $110 \mathrm{~kg}$ ), alimentados com dietas com baixo nível protéico suplementado com aminoácidos sintéticos. Da mesma forma, Figueroa et al. (2000) verificaram redução linear do NUP, à medida que o nível protéico da dieta suplementada com aminoácidos sintéticos diminuiu de 16 para $11 \%$.

Alta correlação entre NUP e o nitrogênio excretado na urina foi observada por Fraga (2002), ao avaliar o efeito de níveis crescentes de lisina total $(0,8$ a $1,4 \%)$ sobre a excreção de nitrogênio em suínos machos castrados (15-30 kg), sugerindo que o NUP é útil para indicar a excreção urinária de nitrogênio. Kerr \& Easter (1995) estimaram que a diminuição de cada percentual na proteína bruta da dieta pode reduzir aproximadamente $8 \%$ de nitrogênio excretado no meio. Dessa maneira, menor NUP indica menor excreção de nitrogênio para o meio ambiente.

A dieta com redução de $10 \%$ da PB e suplementada com aminoácidos foi a que resultou em menor nível de NUP $(36,7 \%$ em relação à dieta com elevado teor de PB), o que pode significar menor excreção de nitrogênio, refletindo melhor eficiência de utilização de aminoácidos dietéticos pelos suínos. Da mesma forma, a dieta com redução de $5 \%$ de $\mathrm{PB}$ e suplementada com aminoácidos diminuiu em $23,7 \%$ o NUP.

Não houve efeito $(\mathrm{P}>0,05)$ do nível de $\mathrm{PB}$ da dieta, com ou sem correção de aminoácidos, sobre o EUNG (Tabela 6). Entretanto, analisando os resultados de NUP e os de EUNG, verificou-se que, embora não tenha havido diferença $(\mathrm{P}>0,05)$ para a $E U N G, o$ valor observado para os animais alimentados com dieta com 16,86\% de PB e correção de aminoácidos para proteína ideal apresentou comportamento oposto ao de NUP, ou seja, menor valor de NUP $(9,85)$ e maior de EUNG $(20,29)$, sugerindo melhor eficiência de utilização de aminoácidos dietéticos pelos suínos, nesta situação.

Os resultados da análise econômica encontram-se na Tabela 7. O custo em ração, por quilograma de peso vivo ganho, foi semelhante $(\mathrm{P}>0,05)$ para todos os tratamentos.

Estes resultados demonstram que é possível produzir suínos mais eficientemente sem aumentar os 
custos de produção, com a vantagem de menor impacto ambiental, aplicando o conceito de proteína ideal na formulação das rações.

\section{Conclusões}

Dietas de baixo teor de proteína bruta, com suplementação de aminoácidos sintéticos, formuladas com base no conceito de proteína ideal, não prejudicam o desempenho de leitões dos 15 ao $30 \mathrm{~kg}$ e as variáveis econômicas e, ainda, proporcionam redução da excreção de nitrogênio.

\section{Literatura Citada}

BARBOSA, H.P.; FIALHO, E.T.; FERREIRA, A.S. et al. Triguilho para suínos nas fases inicial de crescimento, crescimento e terminação. Revista Brasileira de Zootecnia, v. 21, n. 5, p. $827-837,1992$.

BELLAVER, C.; FIALHO, E.T.; PROTAS, J.F.S. et al. Radícula de malte na alimentação de suínos em crescimento e terminação. Pesquisa Agropecuária Brasileira, v.20, n.8, p.969-974, 1985

BENATI, M. Níveis nutricionais utilizados nas dietas de suínos. In: SIMPÓSIO INTERNACIONAL SOBRE EXIGÊNCIAS NUTRICIONAIS DE AVES E SUÍNOS, 1996, Viçosa, MG. Anais...Viçosa, MG: Universidade Federal de Viçosa, 1996. p. 447-457.

CAI, Y.; ZIMMERMAN, D.R.; EWAN, R.C. Diurnal variation in concentrations of plasma urea nitrogen and amino acids in pigs given free access to feed or fed twice daily. Journal of Nutrition, v.124, p.1088-1093, 1994.

CANH, T.T.; AARNINK, A.J.A.; SCHUTTE, J.B. et al. Dietary protein affects nitrogen excretion and ammonia emission from slurry of growing-finishing pigs. Livestock Production Science, v.56, p.181-191, 1998 .

CHUNG, T.K.; BAKER, D.H. Ideal amino acid pattern for 10kilogram pigs. Journal of Animal Science, v.70, p.31023111, 1992.

COELHO, L.S.S.; COSTA, P.M.A.; SILVA, M.A. et al. Exigência de lisina de suínos de 15 a $30 \mathrm{~kg}$ de peso vivo em rações de baixo nível protéico. Revista Brasileira de Zootecnia, v.16, n.1, p.60-71, 1987.

D'MELLO, J.P.F. Amino acid-supplementation of cereal-based diets for non-ruminants. Animal Feed Science and Technology, v.45, n.1, p.1-18, 1993 (Abstract).

FRAGA, A.L. Exigência de lisina para suínos em fase inicial (15 a $30 \mathrm{~kg})$, de dois grupos genéticos, em rações formuladas de acordo com o conceito de proteína ideal Maringá: Universidade Estadual de Maringá, 2002. 46p. Dissertação (Mestrado em Zootecnia) - Universidade Estadual de Maringá, 2002.

FERREIRA, R.A.; OLIVEIRA, R.F.M.; DONZELE, J.L. et al. Redução da proteína bruta e suplementação de aminoácidos em rações para suínos machos castrados dos 15 a $30 \mathrm{~kg}$ mantidos em estresse de calor $\left(32^{\circ} \mathrm{C}\right)$. In: REUNIÃO ANUAL DA SOCIEDADE BRASILEIRA DE ZOOTECNIA, 38. 2001, Piracicaba. Anais... Piracicaba: Sociedade Brasileira de Zootecnia, 2001. p.874-876.
FIGUEROA, J.L.; LEWIS, A.J.; MILLER, P.S. Nitrogen balance and growth trials with pigs fed low-crude protein, amino acid-supplemented diets. Nebraska Swine Report, p.26-28, 2000 .

HAHN, J.D.; BAKER, D.H. Optimum ratio of threonine, tryptophan, and sulfur amino acids for finishing swine. Journal of Animal Science, v.73, p.482-489, 1995.

HANSEN, J.A.; KNABE, D.A.; BURGOON, K.G. Amino acid supplementation of low-protein sorghum - soybean meal diets for 5- to 20- kilogram swine. Journal of Animal Science, v.71, p.452-458, 1993.

KERR, B.J.; McKEITH, F.K.; EASTER, R.A. Effect on performance and carcass characteristics of nursery to finisher pigs fed reduced crude protein, amino acid supplemented diets. Journal of Animal Science, v.73, p.433-440, 1995.

KERR, B.J.; EASTER, R.A. Effect of feeding reduced protein, amino acid-supplemented diets on nitrogen and energy balance in grower pigs. Journal of Animal Science, v.73, p.3000-3008, 1995.

KENDALL, D.C.; LEMENAGER, K.M.; RICHERT, B.T. et al. "Effects of intact protein diets versus reduced crude protein diets supplemented with synthetic amino acids on pig performance and ammonia levels in swine buildings", 1998, <http://www.ansc.purdue.edu/swine/ swineday/sday98/psd20-98.htm (01/2002).

KNOWLES, T.A.; SOUTHERN, L. L.; BIDNER, T.D. et al. Effect of dietary fiber or fat in low-crude protein, crystalline amino acid-supplemented diets for finishing pigs. Journal of Animal Science, v.76, p.2818-2832, 1998.

Le BELLEGO, L.; NOBLET. J. Performance and utilization of dietary energy and amino acids in piglets fed low protein diets. Livestock Production Science, v.76, n.1-2, p.45-58, 2002.

LEE, K.U.; BOYD, R.D.; AUSTIC, R.E. et al. Influence of the lysine to protein ratio in practical diets on the efficiency of nitrogen use growing pigs. Asian Australasian Journal of Animal Sciences, v.11, n.6, p.718-724, 1998 (Abstract).

LEWIS, A.J. Amino acids in swine nutrition. In: LEWIS, A.J.; SOUTHERN, L.L. (Eds.) Swine nutrition. 2.ed. Boca raton: CRC Press, 2001. p. 131-141.

LI, D.F.; XI, P.B.; WANG, J.X. et al. The effect of lysine to protein ratio on growth performance and efficiency of nitrogen utilization in pigs. Asian Australasian Journal of Animal Sciences, v.14, n.19, p.1282-1289, 2001 (Abstract).

MOREIRA, I.; KUTSCHENKO, M.; FURLAN, A.C. et al. Exigência de lisina para suínos em crescimento, alimentados com baixo teor de proteína, baseado no conceito de proteína ideal. In: REUNIÃO ANUAL DA SOCIEDADE BRASILEIRA DE ZOOTECNIA, 38., 2001, Piracicaba. Anais... Piracicaba: SBZ, 2001. p.770-771.

NATIONAL RESEARCH COUNCIL - NRC. Nutrients requirement of swine. 10.ed. Washington, D.C.: National Academy of Science, 1998. 189p.

NEWMAN, D.J.; PRICE, C.P. Renal function and nitrogen metabolites. In: BURTIS, C.A.; ASHWOOD, E.R. (Eds.) Tietz textbook of clinical chemistry. 3.ed. Philadelphia: W. B. Saunders Company, 1999. p.1204-1270.

PARSONS, C.M.; BAKER, D.H. The concept and use of ideal protein in the feeding of non-ruminants. In: SIMPÓSIO INTERNACIONAL DE PRODUÇÃO DE NÃO-RUMINANTES, 1994, Maringá. Anais... Maringá: Universidade Estadual de Maringá, 1994. p.119-128. 
PATIENCE, J.F.; AUSTIC, R.E.; BOYD, D. Effect of dietary electrolyte balance on growth and acid-base status in swine. Journal of Animal Science, v.64, p.457-466, 1987.

PATIENCE, J.F.; CHAPLIN, R.K. The relationship among dietary undetermined anion, acid-base balance, and nutrient metabolism in swine. Journal of Animal Science, v.75, p.2445-2452, 1997.

PERDOMO, C.C.; LIMA, G.J.M.M. Considerações sobre a questão dos dejetos e o meio ambiente. In: SOBESTIANSKY, J.; WENTZ, I.; SILVEIRA, P.R.S. et al. (Eds.) Suinocultura Intensiva - Produção, manejo e saúde do rebanho. Concórdia: Embrapa-CNPSA, 1994. p.223-235.

PIETERSE, E.; SIEBRITS, F.K.; GLOY, E.L. et al. The effect of protein inclusion level in diets formulated to contain an ideal amino acid composition for growing pigs. South African Journal of Animal Science, v.30, n.1, p.57-61, 2000.

POZZA, P.C.; GOMES, P.C.; DONZELE, J.L. et al. Exigência de treonina digestível para suínos machos castrados dos 15 a $30 \mathrm{~kg}$. Revista Brasileira de Zootecnia, v.28, n.3, p.560-568, 1999 .
ROSTAGNO, H.S.; ALBINO, L.F.T.; DONZELE, J.L. et al. Tabelas brasileiras para aves e suínos - Composição de alimentos e exigências nutricionais. Viçosa, MG: Universidade Federal de Viçosa, 2000. 141p.

SUIDA, D. Formulação por proteína ideal e conseqüências técnicas, econômicas e ambientais. In: SIMPÓSIO INTERNACIONAL DE NUTRIÇÃO ANIMAL, 1., 2001, Santa Maria. Anais... Santa Maria: 2001. p.1-17.

TUITOEK, K.; YOUNG, L.G.; LANGE, C.F.M. et al. The effect of reducing excess dietary amino acids on growing-finishing pig performance: an evaluation of the ideal protein concept. Journal of Animal Science, v.75, p.1575-1583, 1997.

Recebido em: 06/01/03

Aceito em: $11 / 05 / 04$ 